\title{
ANALISIS PRODUKTIVITAS TENAGA KERJA PADA PEKERJAAN KOLOM DI PROYEK PEMBANGUNAN GEDUNG PEMDA KABUPATEN SUKABUMI
}

\author{
Nia Kartika, Siti Muawanah Robial dan Agung Pratama \\ Program Studi Teknik Sipil, Fakultas Sains dan Teknologi, Universitas Muhammadiyah Sukabumi \\ Jl. R. Syamsudin, S.H., No.50 Kota Sukabumi \\ e-mail : niakartika@ummi.ac.id
}

\begin{abstract}
Construction management is an effort in managing projects in the construction sector that goes according to planning, one of which is resource management which is included in the scope of construction management. To regulate the use of labor, the contractor must know the level of worker productivity. The productivity of workers will greatly affect the profit or loss of a project, this is because the level of worker productivity is related to the cost of wages for the realization of the labor required. To analyze this productivity, several methods can be used, including the Work sampling method. This method is used to determine how much labor productivity in the Sukabumi District Government Building Construction project on column work consisting of reinforcement work, formwork, and casting in this study. Research procedures carried out are starting with a literature study. This activity is carried out both before and after the researcher has successfully identified the problem. Then the field study (direct observation) by measuring the productivity of the workers doing the work, and taking the necessary data. In researching the field, the number of workers observed in this project was workers who worked from the beginning of the process until the completion of work in each area that was worked on. There are 5 workers with a duration of 10 days. From the calculation results, it is obtained that the standard time which also shows the amount of labor productivity in column work with concrete structures for reinforcement work is $3.907 \mathrm{~kg} /$ minute, then for formwork work is $11,951 / \mathrm{m} 2$ and for casting work is $17,727 / \mathrm{m} 3$. Then the labor coefficient is obtained for $0.065 \mathrm{OH}$ for reinforcement work, $0.199 \mathrm{OH}$ for formwork work, and $0.295 \mathrm{OH}$ for casting work.
\end{abstract}

Keywords: Labor, productivity, work sampling

\begin{abstract}
Abstrak : Manajemen konstruksi adalah upaya dalam mengatur proyek dalam bidang konstruksi bisa berjalan sesuai dengan perencanaan, salah satunya adalah manajemen sumber daya yang termasuk dalam cakupan dari manajemen konstruksi. Dalam upaya mengatur penggunaan tenaga kerja, maka kontraktor harus mengetahui tingkat produktivitas pekerja. Produktivitas pekerja akan sangat berpengaruh terhadap keuntungan atau kerugian suatu proyek, hal ini dikarenakan tingkat produktivitas pekerja berhubungan dengan biaya upah realisasi tenaga kerja yang diperlukan. Untuk menganalisis produktivitas ini ada beberapa metode yang bisa digunakan, antara lain metode Work sampling. Metode ini digunakan untuk mengetahui seberapa besar produktivitas tenaga kerja di proyek Pembangunan Gedung Pemda Kabupaten Sukabumi pada pekerjaan kolom yang terdiri dari pekerjaan pembesian, bekisting dan pengecoran pada penelitian ini. Prosedur Penelitian yang dilakukan adalah dimulai dengan studi literatur. Kegiatan ini dilakukan baik sebelum maupun sesudah peneliti berhasil mengindentifikasi masalah. Kemudian studi lapangan (pengamatan langsung) dengan melakukan pengukuran produktivitas terhadap pekerja yang melakukan pekerjaan, dan mengambil data-data yang diperlukan. Pada pelaksanaan penelitian di lapangan, jumlah pekerja yang diamati dalam proyek ini adalah pekerja yang bekerja dari awal proses hingga selesainya pekerjaan di setiap area yang dikerjakan. Pekerja yang diamatai sebanyak 5 orang pekerja dengan durasi 10 hari. Dari hasil perhitungan didapat waktu baku yang juga menunjukkan besarnya produktivitas tenaga kerja pada pekerjaan kolom dengan struktur beton untuk pekerjaan pembesian adalah 3,907 kg/menit, kemudian untuk pekerjaan bekisting adalah $11,951 / \mathrm{m} 2$ dan untuk pekerjaan pengecoran adalah 17,727/m3 Kemudian untuk koefisien tenaga kerja didapat sebesar $0.065 \mathrm{OH}$ untuk pekerjaan pembesian, 0.199 $\mathrm{OH}$ untuk pekerjaan bekisting dan $0.295 \mathrm{OH}$ untuk pekerjaan pengecoran.
\end{abstract}

Kata kunci : Tenaga kerja, produktivitas, work sampling 


\section{PENDAHULUAN}

Proyek konstruksi adalah salah satu kegiatan yang hasil dari pekerjaannya dipengaruhi oleh produktivitas tenaga kerjanya. Kegiatan di proyek konstruksi saling berkaitan, sehingga bila salah satu kegiatan terhambat maka akan menghambat kegiatan lainnya di lapangan. Begitupun kegiatan konstruksi itu adalah pekerjaan yang kompleks dan memerlukan perhatian yang lebih dalam peleksanaannya. Elemen yang menjadi bagian dalam konstruksi adalah biaya, mutu dan waktu yang didalamnya juga ada sumber daya yang harus dikendalikan, seperti pekerja dan material.

Sumber daya manusia di proyek konstruksi, salah satunya adalah pekerja yang menjadi pelaksana teknis di lapangan, sangat mempunyai peran yang besar dalam keberhasilan sebuah proyek konstruksi. Sehingga peran pekerja lapangan ini harus mendapat perhatian secara serius dalam pencapaian target pekerjaan di lapangan. Target pekerjaan yang sudah ditetapkan akan tercapai ketika para pekerja di lapangan memiliki produktivitas yang optimal serta keterampilan yang sesuai.

Segala jenis pekerjaan yang dikerjakan di proyek disesuaikan dengan volume pekerjaan yang telah direncanakan. Perbandingan antara volume pekerjaan dengan jumlah waktu dan tenaga kerja yang dibutuhkan untuk menyelesaikan pekerjaan tersebut dikenal dengan istilah produktivitas tenaga kerja. Dalam upaya mengatur atau memanajemen penggunaan tenaga kerja, maka kontraktor harus mengetahui tingkat produktivitas pekerja. Produktivitas pekerja akan sangat berpengaruh terhadap keuntungan atau kerugian suatu proyek, hal ini dikarenakan tingkat produktivitas pekerja berhubungan dengan biaya upah realisasi tenaga kerja yang diperlukan.

Salah satu pekerjaan yang utama dalam proses pembangunan gedung adalah pekerjaan struktur, salah satunya pekerjaan kolom dengan beton. Hal ini dikarenakan pekerjaan struktur kolom, merupakan pekerjaan struktur yang menentukan kelanjutan dari pekerjaan yang berada diatas lantai tersebut, khususnya pada pekerjaan gedung dua lantai atau lebih. Sehingga perlu dianalisis produktivitas pekerjanya agar bisa melakukan evaluasi dan percepatan dengan cara-cara peningkatan yang dilakukan ke depannya.
Untuk menganalisis produktivitas ini ada beberapa metode yang bisa digunakan, namun metode-metode yang ada memiliki tingkat akurasi yang belum maksimal karena perilaku pekerja tidak bisa diprediksi akan tetap. Oleh karena itu, metode-metode pendekatan biasanya dilakukan untuk mengukur produktivitas pekerja antara lain metode Work sampling. Metode ini dilakukan dengan menentukan waktu-waktu yang akan melihat para tenaga kerja dan pekerjaannya secara acak sesuai dengan bilangan acak yang telah ditetapkan terlebih dahulu. Melalui pengamatan pada waktu-waktu acak tersebut dapatlah ditarik kesimpulan tentang ada tidaknya suatu kejadian. Semakin banyak bilangan acak atau semakin banyaknya waktu pengamatan yang dilakukan maka akan semakin besar kemungkinan keterangan kegiatan mendekati gambaran yang sebenarnya.

Maka dengan latar belakang tersebut, penelitian ini memiliki rumusan masalah tentang seberapa besar produktivitas tenaga kerja di proyek Pembangunan Gedung Pemda Kabupaten Sukabumi pada pekerjaan kolom beton. Adapun tujuan penelitian ini adalah untuk dapat mengetahui besarnya produktivitas tenaga kerja serta alokasi pemanfaatan waktu oleh para tenaga kerja dalam melaksanakan pekerjaan kolom beton selama waktu kerjanya dengan mengadakan pengukuran secara langsung yaitu dengan menggunakan metode Work sampling pada proyek Pembangunan Gedung Pemda Kabupaten Sukabumi.

\section{TINJAUAN PUSTAKA}

\section{Sumber Daya Proyek}

Sumber daya proyek merupakan elemen yang paling strategik dalam organisasi, terutama sumber daya manusia. Peningkatan produktivitas hanya dapat dilakukan oleh manusia, demikian juga sumber daya manusia yang dapat menyebabkan terjadinya pemborosan dan efisiensi dalam berbagai bentuknya. Mengingat bahwa pada umumnya proyek berlangsung dengan kondisi yang berbeda - beda, maka dalam merencanakan tenaga kerja hendaknnya dilengkapi dengan analisis produktivitas dan indikasi variabel yang mempengaruhi (Soeharto,1995).

\section{Produktivitas}

Secara umum produktivitas diartikan sebagai hubungan antara hasil nyata maupun fisik dengan masukan sebenarnya. Suatu 
perbandingan antara output dan input, masukan sering dibatasi dengan masukan tenaga kerja, sedangkan keluaran diukur dalam kesatuan fisik bentuk mental. Produktivitas juga diartikan sebagai tingkatan efisiensi dalam memproduksi barang - barang atau jasa. Ukuran produktivitas yang paling terkenal berkaitan dengan tenaga kerja yang dapat dihitung dengan membagi pengeluaran oleh jumlah yang digunakan atau jam - jam kerja orang (Muchdarsyah, 1992).

L. Greenberg mendefinisikan produktivitas sebagai perbandingan antara totalitas pengeluaran pada waktu tertentu dibagi totalitas pemasukan selama periode tersebut. Dengan demikian produktivitas dapat dirumuskan sebagai berikut :

$\boldsymbol{O}=P / I$

Dimana :

$\mathrm{P}=$ Produktivitas (m2/menit)

$\mathrm{O}=$ Output (m2)

$\mathrm{I}=$ Input (menit)

Ukuran Output (O) dapat dinyatakan antara lain dalam bentuk :

- Jumlah satuan fisik produk/jasa

- Nilai rupiah produk/jasa

Ukuran Input (I) dapat dinyatakan antara lain dalam bentuk :

- Jumlah waktu

- Jumlah tenaga kerja

- Jumlah biaya tenaga kerja

- Jumlah material

Untuk satuan dari Output $(\mathrm{O})$ sebagai jumlah satuan fisik produk bisa dinyatakan dalam $\mathrm{m}^{2}$, dan untuk satuan dari Input (I) sebagai jumlah waktu bisa dinyatkan dalam menit, dengan demikian satuan dari produktvitas (P) bisa dinyatakan dalam bentuk $\mathrm{m}^{2} /$ menit.

Bekerja yang effektif menurut jumlah jam kerja yang seharusnya serta kerja yang sesuai dengan uraian kerja masing-masing pekerja, akan dapat menunjang kemajuan serta mendorong kelancaran usaha baik secara individu maupun secara menyeluruh. Banyak kejadian disekitar kita betapa pemanfaatan waktu kerja yang merupakan upaya paling dasar dari produktivitas kerja, banyak diabaikan, bahkan secara sengaja dilanggar. Kerja produktif memerlukan ketrampilan kerja yang sesuai dengan isi kerja sehingga bisa menimbulkan penemuan - penemuan baru untuk memperbaiki cara kerja atau minimal mempertahankan yang sudah baik. Kerja produktif memerlukan prasarat lain sebagai pendukung yaitu: Kemauan kerja yang tinggi, lingkungan kerja yang nyaman, penghasilan yang dapat memenuhi kehidupan minimum, jaminan sosial yang memadai, kondisi kerja yang manusiawi dan hubungan kerja yang harmonis.

\section{Tenaga Kerja}

Tenaga kerja merupakan salah satu unsur penting dalam pelaksanaan suatu proyek karena pengaruhnya yang cukup besar terhadap biaya dan waktu penyelesaian suatu pekerjaan proyek. Namun perlu diperhatikan juga bahwa manusia merupakan sumber daya yang komplek dan sulit diprediksi sehingga diperlukan adanya usaha dan pemikiran lebih mendalam dalam pengelolaan tenaga kerja.

Dalam pelaksanaan pekerjaan, tenaga kerja dibagi beberapa bagian sebagai berikut.

a. Tenaga kerja ahli, adalah pegawai yang ditempatkan dalam pekerjaan proyek yang sedang berlangsung. Jenis tenaga kerja ini memegang peranan yang penting terhadap sistem koordinasi dan sistem manajemen dengan tenaga kerja lainnya untuk menghasilkan prestasi yang baik dalam melaksanakan pekerjaan. Meliputi tenaga pelaksana yang tingkat pendidikannya sarjana, sarjana muda dan memiliki pengalaman dibidang masing-masing.

b. Mandor, dituntut untuk memiliki pengetahuan teknis dalam taraf tertentu, misalnya: dapat membaca gambar konstruksi, dapat membuat perhitungan ringan, dapat membedakan kualitas bahan bangunan yang akan digunakan, menangani pekerjaan acuan, pembesian, pengecoran, dan mengawasi pekerjaan tenaga kerja bawahannya.

c. Tenaga tukang, harus ahli dalam bidangnya berdasarkan pengalaman dan cara kerja yang sederhana. Tukang dalam proyek dibagi menjadi lima bagian yaitu tukang besi, tukang batu, tukang kayu, tukang las, dan tukang listrik. Tukang besi mengurusi segala macam kegiatan yang berhubungan degan pembesian/pemasangan tulangan, tukang batu bertugas dalam pengecoran dan pembuatan lantai kerja, tukang kayu bertugas untuk mengurusi segala macam pekerjaan yang berhubungan dengan kayu baik bekesting hingga servis lainnya.

d. Tenaga kasar, memerlukan kondisi yang kuat dan sehat untuk pengangkutan bahan, alat, dan lain - lain. 
e. Tenaga keamanan (security), bertugas menjaga keamanan lokasi proyek, prosedur penerimaan tamu serta membuka dan menutup pintu jika ada concrete mixer truck, concrete pump truck maupun truk bahan bangunan yang akan masuk ke lokasi proyek.

Bila dilihat dari bentuk hubungan kerja antara pihak yang bersangkutan, maka tenaga kerja proyek khususnya tenaga kerja konstruksi dibedakan menjadi dua, yaitu:

1. Tenaga kerja borongan, tenaga kerja berdasarkan ikatan kerja yang ada antara perusahaan penyedia tenaga kerja (labour supplier) dengan kontraktor untuk jangka waktu tertentu.

2. Tenaga kerja langsung (direct hire), tenaga kerja yang direkrut dan menandatangani ikatan kerja perorangan dengan perusahaan kontraktor. Umumnya diikuti dengan latihan, sampai dianggap cukup memiliki kemampuan dan kecakapan dasar.

Ukuran produktivitas yang sering diamati adalah berkaitan dengan tenaga kerja. Pengertian tenaga kerja menurut Undangundang Republik Indonesia No.13 Tahun 2003 adalah setiap orang yang mampu melakukan pekerjaan guna menghasilkan barang dan/atau jasa baik untuk memenuhi kebutuhan sendiri maupun masyarakat.

\section{Produktivitas Tenaga Kerja}

Secara umum, produktifitas merupakan perbandingan antara output dan input. Dibidang konstruksi, output dapat dilihat dari kuantitas pekerjaan yang telah dilakukan seperti meter kubik galian atau timbunan, ataupun meter persegi untuk plesteran. Sedangkan input-nya merupakan jumlah sumber daya yang dipergunakan seperti tenaga kerja, peralatan dan material. Karena peralatan dan material biasanya bersifat standar, maka tingkat keahlian tenaga kerja merupakan salah satu faktor penentu produktivitas.

Untuk menyelenggarakan proyek, salah satu sumber daya yang menjadi faktor penentu keberhasilannya adalah tenaga kerja. Penyediaan jumlah tenaga kerja, jenis keterampilan, dan keahlian harus mengikuti tuntutan perubahan kegiatan yang sedang berlangsung. Berdasarkan pada kenyataan tersebut, maka suatu perencanaan tenga kerja proyek yang menyeluruh dan terperinci harus meliputi perkiraan jenis dan keperluan tenaga kerja, seperti tenaga ahli dari berbagai disiplin ilmu dan pekerja lapangan untuk tahap konstruksi.

Jenis dan intensitas kegiatan proyek dapat berubah cepat sepanjang siklusnya sehingga penyedian jumlah tenaga kerja, jenis keterampilan dan keahlian harus mengikuti tuntutan perubahan kegiatan yang sedang berlangsung. Untuk itulah diperlukan suatu parameter yang sangat penting yaitu produktifitas tenaga kerja yang digunakan untuk mengukur efisiensi kerja. Menurut Soeharto (1997), definisi indeks produktifitas dapat dirumuskan sebagai berikut :

Produktivitas $=\frac{\text { Volume Pekerjaan }}{\frac{\text { Durasi }}{60} \times \text { Jumlah Pekerja }}$

Kondisi standar adalah kondisi rata-rata dimana indeks produktifitas diberi angka $=1,0$. Jika indeks produktifitas $>1,0$ berarti produktifitas tenaga kerja kurang dari standar. Sebaliknya, jika indeks produktifitas $<1,0$ berarti produktifitas tenaga kerja melebihi standar yang ditetapkan (Soeharto, 1997).

\section{Pengukuran Produktivitas Tenaga Kerja}

Selama berlangsungnya pekerjaan harus diukur hasil - hasil yang dicapai untuk dibandingkan dengan rencana semula. Obyek pengawasan ditujukan pada pemenuhan persyaratan minimal segenap sumber daya yang dikerahkan agar proses kontruksi secara teknis dapat berlangsung baik. Upaya mengevaluasi hasil pekerjaan untuk mengetahui penyebab penyimpangan terhadap estimasi semula. Pemantauan (monitoring) berarti melakukan observasi dan pengujuian pada tiap interval tertentu untuk memeriksa kinerja maupun dampak sampingan yang tidak diharapkan (Istimawan, 1996) .

Karena dalam rangka mengajukan tender, produktivitas tenaga kerja akan besar pengaruhnya terhadap total biaya proyek, minimal pada aspek jumlah tenaga kerja dan fasilitas yang diperlukan. Salah satu pendekatan untuk mencoba mengukur hasil guna tenaga kerja adalah dengan memakai parameter indeks produktivitas (Soeharto, 1995)

Salah satu pendekatan untuk mengetahui tingkat produktivitas tenaga kerja adalah dengan menggunakaan metode yang mengklasifikasikan aktivitas pekerja. Dalam penelitian ini pengamatan dilakukan dengan metode produtivity rating, dimana aktivitas pekerja diklasifikasikan dalam 3 hal yaitu 
Essential contributory work, Effective work (pekerjaan efektif), dan Not Useful (pekerjaan tidak efektif).

a. Essential contributory work, yaitu pekerjaan yang tidak secara langsung, namun bagian dari penyelesaian pekerjaan. Misalnya :

- Menunggu tukang yang lain dengan tidak bekerja.

- Mengangkut peralatan yang berhunungan dengan pekerjaan

- Membaca gambar proyek.

- Menerima instruksi pekerjaan.

- Mendiskusikan pekerjaan

b. Pekerjaan effektif (effective work), yaitu disaat pekerja melakukan pekerjaannya dizona pekerjaan.

c. Pekerjaan tidak efektif (not useful), yaitu kegiatan selain diatas yang tidak menunjang penyelesaian pekerjaan. Seperti meninggalkan zona pengerjaan, berjalan di zona pengerjaan dengan tangan kosong dan mengobrol sesama pekerja sehingga tidak maksimalnya bekerja.

Sehingga faktor utilitas pekerja (LUR) dapat dihitung :

$\boldsymbol{L U} \boldsymbol{R}=\frac{\text { Effective Work }+\frac{1}{4} \text { Essential Contributory Work }}{\text { TOTAL }}$

Pengamatan total $=$ waktu efektif + waktu kontribusi + waktu tidak efektif untuk sebuah tim kerja dikatakan mencapai waktu efektif atau memuaskan bila faktor utilitas pekerjanya lebih dari $50 \%$.

Pengukuran produktivitas tenaga kerja menurut sistem pemasukan fisik perorangan/per-orang atau per jam kerja orang diterima secara luas, namun dari sudut pandang pengawasan harian, pengukuran - pengukuran tersebut pada umumnya tidak memuaskan, dikarenakan adanya variasi dalam jumlah yang diperlukan untuk memproduksi satu unit produk yang berbeda. Oleh karena itu, digunakan metode pengukuran waktu tenaga kerja (Jam, hari atau tahun).

Pengeluaran diubah kedalam unit - unit pekerja yang biasanya diartikan sebagai jumlah kerja yang dapat dilakukan dalam satu jam oleh pekerja yang terpercaya yang bekerja menurut pelaksanaan standar. Karena hasil maupun masukan dapat dinyatakan dalam waktu, produktivitas tenaga kerja dapat dinyatakan sebagai suatu indeks yang sangat sederhana:
$\boldsymbol{P W T K}=\frac{\text { hasil dalam jam }- \text { jam standar }}{\text { masukan dalam jam-jam standar }}$

Waktu efektif adalah waktu dimana pekerja melakukan aktivitas yang dapat dikualifikasikan sebagai bekerja (working). Waktu tidak efektif adalah waktu dimana pekerja melakukan aktivitas yang dapat dikualifikasikan sebagai tidak bekerja (not working). Kualifikasi aktivitas pekerja dalam metode ini tidaklah absolute, artinya dapat menyesuaikan dengan kondisi dilapangan untuk mendapatkan data yang diperlukan.

\section{Metode Work sampling}

Dalam ilmu teknik tata kerja, pengukuran waktu dapat dibagi dalam dua bagian, yaitu pengukuran waktu secara langsung dan secara tidak langsung. Cara langsung ialah si pengukur berada ditempat pekerjaan yang sedang diukur dan mengamati jalannya pekerjaan. Cara langsung ini terdiri dari dua macam yaitu cara jam henti dan cara uji petik pekerjaan (Work sampling). Untuk cara jam henti si pengukur harus berada terus menerus di tempat para tenaga kerja yang akan diukurnya dan mencatat pencapaian satu siklus pekerjaan dengan melihat jam henti (stopwatch) sebagai alat utamanya. Sedangkan untuk Metode Work sampling, pengukur menentukan waktu-waktu yang dia akan melihat para tenaga kerja dan pekerjaannya secara acak sesuai dengan bilangan acak yang telah ditetapkan terlebih dahulu. Jadi tidak secara terus-menerus pengukur berada dan mengamati kegiatan para tenaga kerja.

Melalui pengamatan pada waktu-waktu acak tersebut dapatlah ditarik kesimpulan tentang ada tidaknya suatu kejadian. Akan terlihat pula semakin banyak bilangan acak atau semakin banyaknya waktu pengamatanyang dilakukan maka akan semakin besar kemungkinan keterangan kegiatan mendekati gambaran yang sebenarnya dengan kata lain akan semakin kuat dasar untuk mengambil kesimpulan. Dari catatan yang dilakukan setiap kali pengamatan dapat dilihat berbagai kegiatan yang terjadi serta frekuensi kegiatan yang teramati. Dengan mempelajari frekuensi setiap kegiatan dapat diketahui alokasi pemanfaatan waktu pekerjaan para tenaga kerja (kelompok pekerja). Jika dibandingkan dengan cara pengambilan data yang lain, maka Metode Work sampling ini lebih menghemat waktu, biaya dan tenaga. 


\section{METODE PENELITIAN}

\section{Lokasi Penelitian}

Penelitian ini mengambil lokasi pada Proyek Pembangunan Gedung Pemda Kabupaten Sukabumi, yang berlokasi di Palabuhan Ratu, Kabupaten Sukabumi. Obyek yang diteliti sebagai sumber data (responden) pada penelitian ini adalah adalah produktivitas pekerja dengan pada pekerjaan struktur beton kolom, dan dilakasanakan selama 10 hari.

\section{Metode Pengumpulan Data}

Pada penelitian ini, peneliti menggunakan metode Deskriptif Kuantitatif yaitu pengamatan langsung (observasi) dan wawancara langsung di lapangan. Metode tersebut diambil karena sumber data yang digunakan penulis adalah pekerja yang sedang bekerja, agar diperoleh data yang valid dan aktual dari lapangan.

Pengamatan langsung (observasi) dilakukan untuk mendapatkan data mengenai volume pekerjaan realisasi dalam hal ini adalah pekerjaan bekisting, pembesian, pengecoran hingga pelepasan bekisting pada pekerjaan struktur beton balok lantai satu dan lantai dua, mencatat absensi tenaga kerja yang bekerja selama proses pekerjaan. Sedangkan wawancara dilakukan untuk mendapatkan data yang sifatnya tidak kasat mata yaitu data biaya upah yang diberikan kepada tenaga kerja..

\section{Prosedur Pelaksanaan Penelitian}

Prosedur Penelitian Dalam penulisan ini metode yang digunakan adalah :

- Studi literatur (kepustakaan) Studi kepustakaan harus dilakukan oleh seorang peneliti. Kegiatan ini dilakukan baik sebelum maupun sesudah peneliti berhasil mengindentifikasi masalah. Dengan melakukan studi kepustakaan peneliti dapat mengkaji teori-teori dalam bidangnya. Kegiatan studi kepustakaan ini sangat menunjang suatu penelitian. Di sini peneliti dapat menghimpun informasi yang berkaitan dengan latar belakang penelitian, teori-teori yang melandasi masalah yang akan diteliti, bahan acuan yang relevan dengan masalah atau topikyang akan diteliti dan hasil-hasil penelitian sejenis sebelumnya. Selain itu studi kepustakaan juga memperdalam dan menambah pengetahuan peneliti dalam hal teori dan metodologi penelitian.

- Studi lapangan (pengamatan langsung) dengan melakukan penelitian atau pengukuran produktivitas terhadap sekelompok pekerja yang melakukan pekerjaan, dan mengambil data-data yang diperlukan dalam proyek pembangunan Gedung Pemda Kabupaten Sukabumi.

\section{PEMBAHASAN}

Penelitian ini dilaksanakan pada Proyek Pembangunan Pemda Kabupaten Sukabumi yang berlokasi di Palabuan Ratu Kabupaten Sukabumi. Proyek Pembangunan Gedung Pemda ini dikerjakan oleh PT. Tahta Djaga Internasional sebagai kontraktor pelaksana dengan nilai proyek sebesar $\mathrm{Rp}$. 48.400.033.000,00 (+ppn) yang dikerjakan selama 203 hari kalender.

Adapun yang diteliti adalah produktivitas pekerja pada jam kerja normal, dengan objek yang di teliti hanya pada pekerjaan struktur beton kolom yang dimulai dari pembesian, pengecoran dan pekerjaan bekisting. Berikut data volume dan koefisien dari struktur beton untuk pekerjaan kolom lantai satu dan dua :

Tabel 1. Data pekerjaan struktur kolom lantai 1 dan 2

\begin{tabular}{clcccc}
\hline NO & \multicolumn{1}{c}{ Pekerjaan } & Sat & $\begin{array}{c}\text { Koefisien } \\
\text { Tenaga Kerja }\end{array}$ & $\begin{array}{c}\text { Kebutuhan } \\
\text { Tenaga Kerja }\end{array}$ & Volume \\
\hline A & Lantai 1 & & & & \\
I & Pekerjaan Kolom K1,uk. 80 x 80 & M3 & & & 11614.91 \\
1 & Pembesian 10 kg besi BJLS 24 & Kg & & & \\
& Pekerja & OH & 0.070 & 813 & \\
& Tukang Besi & OH & 0.070 & 813 & \\
& Kepala Tukang & OH & 0.007 & 81 & \\
& Mandor & OH & 0.004 & 46 & \\
2 & 1 M3 cor beton mutu K-300 & M3 & & & \\
& Pekerja & OH & 0.689 & 36 & \\
& Tukang Batu & OH & 0.138 & 7 & \\
\hline
\end{tabular}




\begin{tabular}{|c|c|c|c|c|c|}
\hline \multirow{6}{*}{3} & Mandor & $\mathrm{OH}$ & 0.069 & 4 & \multirow{6}{*}{261.12} \\
\hline & Pemasangan $1 \mathrm{~m} 2$ Bekisting $2 x$ pakai & M2 & & & \\
\hline & Pekerja & $\mathrm{OH}$ & 0.660 & 172 & \\
\hline & Tukang Kayu & $\mathrm{OH}$ & 0.330 & 86 & \\
\hline & Kepala Tukang & $\mathrm{OH}$ & 0.033 & 9 & \\
\hline & Mandor & $\mathrm{OH}$ & 0.033 & 9 & \\
\hline B & Lantai 2 & & & & \\
\hline II & Pekerjaan Kolom K1,uk. 80 × 80 & M3 & & & \multirow{6}{*}{11734.27} \\
\hline \multirow[t]{5}{*}{1} & Pembesian $10 \mathrm{~kg}$ besi BJLS 24 & $\mathrm{Kg}$ & & & \\
\hline & Pekerja & $\mathrm{OH}$ & 0.070 & 821 & \\
\hline & Tukang Besi & $\mathrm{OH}$ & 0.070 & 821 & \\
\hline & Kepala Tukang & $\mathrm{OH}$ & 0.007 & 82 & \\
\hline & Mandor & $\mathrm{OH}$ & 0.004 & 47 & \\
\hline \multirow[t]{4}{*}{2} & $1 \mathrm{M} 3$ cor beton mutu K-300 & M3 & & & \multirow[t]{4}{*}{52.22} \\
\hline & Pekerja & $\mathrm{OH}$ & 0.689 & 36 & \\
\hline & Tukang Batu & $\mathrm{OH}$ & 0.138 & 7 & \\
\hline & Mandor & $\mathrm{OH}$ & 0.069 & 4 & \\
\hline \multirow[t]{5}{*}{3} & Pemasangan $1 \mathrm{~m} 2$ Bekisting $2 x$ pakai & M2 & & & \multirow[t]{5}{*}{261.12} \\
\hline & Pekerja & $\mathrm{OH}$ & 0.660 & 172 & \\
\hline & Tukang Kayu & $\mathrm{PH}$ & 0.330 & 86 & \\
\hline & Kepala Tukang & $\mathrm{OH}$ & 0.033 & 9 & \\
\hline & Mandor & $\mathrm{OH}$ & 0.033 & 9 & \\
\hline
\end{tabular}

Perhitungan Produktivitas Pekerjaan Kolom

Perhitungan produktivitas tenaga kerja pekerjaan kolom terdiri dari pekerjaan pembesian, pengecoran dan bekisting yang didapat dari data proyek Pembangunan Gedung Pemda Kabupaten Sukabumi. Dalam penelitian ini, pekerjaan pembesian untuk pekerjaan kolom saja, pada pembesian kolom di Gedung Pemda ini, baja tulangan yang akan digunakan di angkat oleh Tower Crane menuju lokasi yang diinginkan, baik pekerjaan pemotongan maupun pembekokan dilakukan oleh para pekerja bagian pembesian di lapangan. Untuk pengambilan data pekerjaan pembesian dilakukan dari mulai persiapan melakukan pekerjaan pembesian, hingga seluruh pekerja berhenti melakukan pekerjaan atau pindah ke zona yang lain. Apabila ada salah satu pekerja meninggalkan pekerjaannya, maka data tersebut dianggap tidak sah dan tidak dapat digunakan dalam penelitian ini, dikarenakan jumlah pekerja dari awal memulai pekerjaan pembesian harus tetap sama sampai selesai melakukan pekerjaan pembesian atau sebelum pindah ke zona selanjutnya. Jumlah pekerja yang didapat dalam proyek ini adalah para pekerja yang bekerja dari awal proses pemasangan tulangan kolom hingga selesainya pekerjaan pembesian kolom di setiap area yang dikerjakan. Pekerja yang diamatai sebanyak 5 orang pekerja dengan durasi 10 hari. Adapun proses perhitungan pekerjaan kolom menggunakan langkah sebagai berikut :

a. Jumlah data pengamatan yang telah dilakukan yaitu selama 10 hari untuk 5 orang tenaga kerja dan masing-masing tenaga kerja sebesar 50 data, jadi :

$$
\begin{aligned}
& =(10 \text { hari }) \times 5 \text { (tenaga kerja }) \times 70 \text { (data }) \\
& =3500 \text { data. }
\end{aligned}
$$

b. Jumlah menit pengamatan selama 10 hari penuh :

$$
\begin{aligned}
& =7(\text { jam }) \times 60 \text { (menit) x } 10 \text { (hari) } \\
& =4200 \text { menit }
\end{aligned}
$$

c. Jumlah data kegiatan produktif teramati :

$$
=3500 \text { data }
$$

d. Persentase produktif :

$$
=(3250 / 3500) \times 100 \%=92,8 \%
$$

e. Jumlah menit produktif :

$=$ Persentase produktif $\mathrm{x}$ Jumlah menit pengamatan

f. Jumlah produk yang dihasilkan :

$=$ hasil produk pembesian $/ \mathrm{kg}$,

bekisting $/ \mathrm{m} 2$ dan pengecoran $/ \mathrm{m} 3$

g. Waktu siklus (Ws) :

$=$ Jumlah menit produktif /Jumlah

h. Faktor penyesuaian (p), cara Westinghouse untuk pembesian :

$$
p=1+0,26=1,26
$$

i. Faktor penyesuaian (p), cara Westinghouse untuk pengecoran :

$$
\mathrm{p}=1+0,09=1,09
$$


j. Faktor penyesuaian (p), cara Westinghouse untuk bekisting :

$$
\mathrm{p}=1+0,12=1,12
$$

k. Waktu normal (Wn) :

$$
\mathrm{Wn}=\mathrm{p} \times \mathrm{Ws}
$$

1. Kelonggaran (I) yang dipakai adalah sebagai berikut :

Keperluan pribadi $=5 \%$

Menghilangkan lelah $=4 \%$

Hambatan tak terhindarkan $=4 \%$

$\operatorname{Jumlah}(\mathrm{I})=13 \%$ m. Waktu baku $(\mathrm{Wb})$ :

$$
\mathrm{Wb}=\mathrm{Wn}+(\mathrm{I} \times \mathrm{Wn})
$$

Setelah diketahui waktu baku, kemudian menghitung koefisien pekerja untuk setiap pekerjaan dari mulai pembesian, bekisting dan pengecoran. Adapun contoh perhitungan masing-masing pekerja dan hasil perhitungan waktu baku keseluruhan untuk setiap pekerjaan

\begin{tabular}{|c|c|c|c|c|c|c|c|c|c|c|c|c|c|c|c|c|c|}
\hline \multirow{2}{*}{ Pekerjaan } & \multicolumn{9}{|c|}{ Pengamatan Ke } & \multicolumn{2}{|c|}{ Deviasi } & \multirow{2}{*}{$\begin{array}{l}\text { Rata- } \\
\text { Rata } \\
\end{array}$} & \multirow[t]{2}{*}{ BKA } & \multirow[t]{2}{*}{ BKB } & \multirow[t]{2}{*}{ Ws } & \multirow[t]{2}{*}{ Wn } & \multirow[t]{2}{*}{$\mathrm{Wb}$} \\
\hline & 1 & 2 & 3 & 4 & 5 & 6 & 7 & 8 & 9 & 10 & & & & & & & \\
\hline Pembesian & 29 & 19 & 29 & 31 & 39 & 19 & 31 & 24 & 32 & 27 & 6.11 & 28 & 46.33 & 9.67 & 3.64 & 3.86 & 4.36 \\
\hline Bekisting & 19 & 20 & 24 & 15 & 18 & 21 & 27 & 13 & 15 & 18 & 4.27 & 19 & 31.81 & 6.19 & 2.47 & 2.77 & 3.13 \\
\hline Pengecoran & 20 & 25 & 27 & 23 & 29 & 30 & 17 & 19 & 24 & 20 & 4.40 & 23.4 & 36.61 & 10.19 & 3.04 & 3.32 & 3.75 \\
\hline \multirow[t]{2}{*}{ Pekerjaan } & \multicolumn{9}{|c|}{ Pengamatan Ke } & \multicolumn{2}{|c|}{ Deviasi } & $\begin{array}{l}\text { Rata- } \\
\text { Rata }\end{array}$ & BKA & $\mathrm{BKB}$ & Ws & Wn & $\mathrm{Wb}$ \\
\hline & 1 & 2 & 3 & 4 & 5 & 6 & 7 & 8 & 9 & 10 & & & & & & & \\
\hline Pembesian & 17 & 26 & 19 & 27 & 23 & 19 & 16 & 15 & 11 & 25 & 5.29 & 19.8 & 35.66 & 3.94 & 2.57 & 2.73 & 3.08 \\
\hline Bekisting & 19 & 20 & 24 & 15 & 18 & 21 & 27 & 13 & 15 & 18 & 4.27 & 19 & 31.81 & 6.19 & 2.47 & 2.77 & 3.13 \\
\hline Pengecoran & 13 & 19 & 28 & 30 & 28 & 31 & 27 & 17 & 19 & 24 & 6.19 & 23.6 & 42.16 & 5.04 & 3.07 & 3.34 & 3.78 \\
\hline \multirow{2}{*}{ Pekerjaan } & \multicolumn{9}{|c|}{ Pengamatan Ke } & \multicolumn{2}{|c|}{ Deviasi } & $\begin{array}{l}\text { Rata- } \\
\text { Rata }\end{array}$ & BKA & BKB & Ws & Wn & $\mathrm{Wb}$ \\
\hline & 1 & 2 & 3 & 4 & 5 & 6 & 7 & 8 & 9 & 10 & & & & & & & \\
\hline Pembesian & 14 & 13 & 19 & 21 & 25 & 20 & 13 & 19 & 28 & 30 & 6.01 & 20.2 & 38.24 & 2.16 & 2.63 & 2.78 & 3.15 \\
\hline Bekisting & 13 & 18 & 27 & 20 & 21 & 32 & 14 & 13 & 19 & 21 & 6.09 & 19.8 & 38.06 & 1.54 & 2.57 & 2.88 & 3.26 \\
\hline Pengecoran & 20 & 19 & 17 & 19 & 20 & 20 & 20 & 17 & 19 & 30 & 3.67 & 20.1 & 31.10 & 9.10 & 2.61 & 2.85 & 3.22 \\
\hline \multirow[t]{2}{*}{ Pekerjaan } & \multicolumn{9}{|c|}{ Pengamatan Ke } & \multicolumn{2}{|c|}{ Deviasi } & $\begin{array}{l}\text { Rata- } \\
\text { Rata }\end{array}$ & BKA & $\mathrm{BKB}$ & Ws & $\mathrm{Wn}$ & $\mathrm{Wb}$ \\
\hline & 1 & 2 & 3 & 4 & 5 & 6 & 7 & 8 & 9 & 10 & & & & & & & \\
\hline Pembesian & 39 & 19 & 31 & 24 & 32 & 27 & 23 & 40 & 15 & 22 & 8.24 & 27.2 & 51.93 & 2.47 & 3.54 & 3.75 & 4.24 \\
\hline Bekisting & 23 & 19 & 16 & 15 & 11 & 25 & 20 & 25 & 22 & 29 & 5.42 & 20.5 & 36.76 & 4.24 & 2.67 & 2.98 & 3.37 \\
\hline Pengecoran & 18 & 27 & 20 & 21 & 32 & 14 & 13 & 19 & 21 & 25 & 5.77 & 21 & 38.32 & 3.68 & 2.73 & 2.98 & 3.36 \\
\hline \multirow[t]{2}{*}{ Pekerjaan } & \multicolumn{9}{|c|}{ Pengamatan Ke } & \multicolumn{2}{|c|}{ Deviasi } & $\begin{array}{l}\text { Rata- } \\
\text { Rata } \\
\end{array}$ & BKA & BKB & Ws & Wn & $\mathrm{Wb}$ \\
\hline & 1 & 2 & 3 & 4 & 5 & 6 & 7 & 8 & 9 & 10 & & & & & & & \\
\hline Pembesian & 25 & 21 & 17 & 27 & 39 & 30 & 33 & 26 & 16 & 19 & 7.35 & 25.3 & 47.35 & 3.25 & 3.29 & 3.49 & 3.94 \\
\hline Bekisting & 18 & 15 & 13 & 27 & 20 & 21 & 27 & 19 & 28 & 30 & 5.87 & 21.8 & 39.40 & 4.20 & 2.83 & 3.17 & 3.59 \\
\hline Pengecoran & 26 & 30 & 21 & 18 & 16 & 19 & 22 & 28 & 30 & 21 & 5.07 & 23.1 & 38.30 & 7.90 & 3.00 & 3.27 & 3.70 \\
\hline \multirow[t]{2}{*}{ Pekerjaan } & \multicolumn{9}{|c|}{ Pengamatan Ke } & \multicolumn{2}{|c|}{ Deviasi } & $\begin{array}{l}\text { Rata- } \\
\text { Rata }\end{array}$ & BKA & BKB & Ws & Wn & $\mathrm{Wb}$ \\
\hline & 1 & 2 & 3 & 4 & 5 & 6 & 7 & 8 & 9 & 10 & & & & & & & \\
\hline Pembesian & 31 & 27 & 17 & 19 & 30 & 19 & 31 & 25 & 17 & 21 & 5.77 & 23.7 & 41.02 & 6.38 & 3.08 & 3.27 & 3.69 \\
\hline Bekisting & 15 & 18 & 22 & 28 & 31 & 30 & 22 & 16 & 19 & 18 & 5.84 & 21.9 & 39.42 & 4.38 & 2.85 & 3.19 & 3.60 \\
\hline
\end{tabular}
disajikan dalam tabel berikut :

Tabel 2. Contoh perhitungan waktu baku untuk pekerja 1 


\begin{tabular}{|c|c|c|c|c|c|c|c|c|c|c|c|c|c|c|c|c|c|}
\hline Pengecoran & 24 & 20 & 17 & 30 & 29 & 30 & 17 & 19 & 24 & 20 & 5.19 & 23 & 38.56 & 7.44 & 2.99 & 3.26 & 3.68 \\
\hline \multirow{2}{*}{ Pekerjaan } & \multicolumn{9}{|c|}{ Pengamatan Ke } & \multicolumn{2}{|c|}{ Deviasi } & $\begin{array}{l}\text { Rata- } \\
\text { Rata }\end{array}$ & BKA & BKB & Ws & Wn & $\mathrm{Wb}$ \\
\hline & 1 & 2 & 3 & 4 & 5 & 6 & 7 & 8 & 9 & 10 & & & & & & & \\
\hline Pembesian & 26 & 21 & 30 & 15 & 27 & 25 & 15 & 18 & 31 & 20 & 5.85 & 22.8 & 40.34 & 5.26 & 2.96 & 3.14 & 3.55 \\
\hline Bekisting & 17 & 14 & 17 & 20 & 22 & 20 & 16 & 25 & 19 & 21 & 3.21 & 19.1 & 28.74 & 9.46 & 2.48 & 2.78 & 3.14 \\
\hline Pengecoran & 24 & 19 & 17 & 30 & 29 & 11 & 15 & 18 & 24 & 20 & 6.04 & 20.7 & 38.81 & 2.59 & 2.69 & 2.93 & 3.31 \\
\hline
\end{tabular}

Setelah didapat waktu baku dari kelima pekerja yang diamati, dijumlahkan kemudian dirata-ratakan untuk setiap pekerjaan dalam struktur kolom. Sebagaimana terlihat dalam tabel berikut :

Tabel 3. Hasil Perhitungan Waktu Baku

\begin{tabular}{|c|c|c|c|c|c|c|c|}
\hline \multirow{2}{*}{ Pekerjaan } & \multicolumn{5}{|c|}{ Waktu Baku Pekerja } & \multirow{2}{*}{ Deviasi } & \multirow{2}{*}{$\begin{array}{c}\text { Rata-Rata Waktu } \\
\text { Baku }\end{array}$} \\
\hline & 1 & 2 & 3 & 4 & 5 & & \\
\hline Pembesian & 3.715 & 3.568 & 4.006 & 4.098 & 4.149 & 0.25 & 3.907 \\
\hline Bekisting & 3.316 & 3.523 & 18.136 & 17.444 & 17.334 & 7.79 & 11.951 \\
\hline Pengecoran & 3.543 & 3.713 & 26.483 & 27.157 & 27.739 & 12.88 & 17.727 \\
\hline
\end{tabular}

Dari tabel di atas bisa dilihat bahwa waktu baku untuk pekerjaan pembesian adalah 3,907 $\mathrm{kg} /$ menit, kemudian untuk pekerjaan bekisting adalah $11,951 / \mathrm{m} 2$ dan untuk pekerjaan pengecoran adalah $17,727 / \mathrm{m} 3$.

Sedangkan untuk koefisien untuk masingmasing pekerjaan dari hasil perhitungan lapangan dibandingkan dengan SNI dapat dilihat dari tabel di bawah ini :

Tabel 4. Koefisien Pekerja

\begin{tabular}{ccc}
\hline \multirow{2}{*}{ Pekerjaan } & \multicolumn{2}{c}{ Koefisien } \\
\cline { 2 - 3 } & Lapangan & SNI \\
\hline Pembesian & 0.065 & 0.070 \\
Bekisting & 0.199 & 0.660 \\
Pengecoran & 0.295 & 0.689 \\
\hline
\end{tabular}

Maka jika dilihat dari koefisien hasil perhitungan di lapangan, lebih kecil dengan SNI yang dijadikan acuan di Rencana Anggaran Biaya pada perencanaan. Untuk pekerjaan pembesian memiliki selisih yang kecil dan pada pekerjaan bekisiting memiliki selisish yang cukup besar jika dibandingkan dengan pekerjaan lainnya.

\section{KESIMPULAN}

Dari hasil penelitian yang dilakukan, dapat ditarik kesimpulan sebagai berikut :

1. Dari hasil perhitungan didapat waktu baku yang juga menunjukkan besarnya produktivitas tenaga kerja pada pekerjaan kolom dengan struktur beton pada proyek pembangunan Gedung Pemda Kabupaten Sukabumi untuk pekerjaan pembesian pada kolom adalah 3,907 kg/menit, kemudian untuk pekerjaan bekisting pada kolom adalah 11,951/m2 dan untuk pekerjaan pengecoran kolom adalah $17,727 / \mathrm{m} 3$.

2. Kemudian untuk koefisien tenaga kerja didapat sebesar $0.065 \mathrm{OH}$ untuk pekerjaan pembesian kolom, $0.199 \mathrm{OH}$ untuk pekerjaan bekisting kolom dan $0.295 \mathrm{OH}$ untuk pekerjaan pengecoran kolom.

\section{SARAN}

Pengawasan yang baik dan intensif merupakan kunci dari optimalnya produktivitas pekerja di lapangan. Sehingga untuk pihak pelaksana konstruksi lebih meningkatkan pengawasan di lapangan dan kedisiplinan pekerja agar target pekerjaan sesuai dengan yang ditetapkan.

\section{DAFTAR PUSTAKA}

Ching, F. D. K. and Adams C. 2002. Ilustrasi Konstruksi Bangunan. Erlangga. Jakarta

Dipohusodo, Istimawan.1995.Manajemen Proyek \& Kontruksi. Jilid 1.Yogyakarta : Badan Penerbit Kanisius.

Ervianto, W. I., Cara Tepat Menghitung Biaya Bangunan. Yogyakarta: Andi. 
Imam Akbar, Muchammad. 2005. Analisis Produktivitas Tukang Kayu Pada Pekerjaa Pemasangan Bakisting Di Kota Denpasar. Tugas Akhir, Jurusan Teknik Sipil,Fakultas Teknik Universitas Udayana, Denpasar.

Ronny Walangitan. Produktivitas Tenaga Kerja Dengan Menggunakan Metode Work sampling Pada Pekerjaan Kolom Dan Balok Mega Trade Center Manado. Tekno-Sipil/Volume 10/No. 57/April 2012

Soeharto, Iman. 1989. Manajemen Proyek: Dari Konseptual Sampai Operasional. Jilid 1. Jakarta : Erlangga. 